\title{
EMMA BARRANDEGUY: VISIBLE / INVISIBLE
}

\section{Emma Barrandeguy: visible / invisible}

\section{Guadalupe Maradei}

\author{
Universidad de Buenos Aires \\ Facultad de Filosofía y Letras \\ Argentina \\ guadaramona@gmail.com
}

Resumen: Se propone una lectura de los modos de configuración como autora de la escritora argentina Emma Barrandeguy (19|4-2006) en la historia de la literatura nacional $-y$, dentro de ella, en la tradición de la literatura lgtb/queer argentina-, haciendo foco, por un lado, en los procesos canonizadores de visibilización / invisibilización y, por otro, en determinadas políticas de escritura y del cuerpo que la autora sostuvo tanto en su producción poética, narrativa y teatral como en su militancia política y en sus modos de vida.

Palabras clave: Emma Barrandeguy; literatura argentina; estudios de género; siglo XX; Argentina

\begin{abstract}
We propose a reading of the forms of configuration as author of the Argentine writer Emma Barrandeguy (19/4-2006) in the history of national literature -and, within it, in the Lgbt/Queer literary tradition of Argentina-, focusing, on the one hand, on the canonizing processes of visibility / invisibility and, on the other hand, in certain writing and body's policies that the author sustained both in her poetic, narrative and theatrical production as well as in her political militancy and in her ways of life.
\end{abstract}

Keywords: Emma Barrandeguy; Argentine Literature; Gender Studies; 20st Century; Argentina 


\section{Visibilización taimada}

U na anciana de melena perlada recorre el cementerio de Gualeguay, su pueblo natal en la Provincia de Entre Ríos, con su amiga, una profesora de la literatura de Paraná, que la visita asiduamente, la provee de noticias del mundo literario y de cigarrillos de marihuana. La anciana se detiene frente a una lápida de mármol de Carrara resquebrajado, señala con el bastón el nombre de la difunta escrito en letras de molde y, sonriéndose, espeta: "Con ella me acosté varias veces. Y con su hermana, que está tres tumbas más allá, también" 1 .

En su último tiempo de vida (murió en 2006 a la edad de 92 años), Emma Barrandeguy se divertía jactándose de sus dotes de seducción que no distinguían género, edad ni nacionalidad. "Envejecer no es triste porque siempre queda el clítoris”, aclaró a María Moreno en una entrevista de 2012. En cambio, era infrecuente encontrar jactancia similar respecto de sus dotes de escritora. Sin afectación, decía convencida a sus entrevistadores/as, discípulos/as o a quien estuviera dispuesto/a a escuchar, que la producción literaria que llevó adelante durante más de setenta ańos -que comprende textos poéticos, dramáticos y narrativos- no tendría gravitación en la historia de la literatura argentina. Tenía razón. Su modo de estar, su lugar en esa configuración histórico-institucional que es la historia de una literatura nacional, se manifiesta como una presencia ingrávida, liviana, tenue ${ }^{2}$.

Pienso este hecho en relación con dos conjuntos de razones. Primero, el controvertido funcionamiento del canon literario occidental y sus procesos de visibilización / invisibilización. Al respecto, fue Griselda Pollock (2002) quien puso en evidencia cómo el canon de la historia del arte y la literatura occidental es uno de los más virulentos y virilentos. El canon, esos textos y objetos de la literatura y el arte que las instituciones académicas y culturales establecen como lo más representativo y significante, lo incuestionablemente grande, es también una proposición acerca de aquello que debe ser estudiado como modelo por quienes que aspiren a esas prácticas artísticas. En las últimas décadas, distintas

1 Entrevista realizada a la Prof. Dra. Claudia Rosa, de la Universidad Nacional de Entre Ríos en el marco de una investigación posdoctoral radicada en la Facultad de Filosofía y Letras de la Universidad de Buenos Aires y en la construcción que estoy llevando adelante de un Fondo de Archivo de la escritora en el Centro de Documentación e Investigación de las Culturas de Izquierda (CeDiNCI) sito en la Ciudad Autónoma de Buenos Aires.

2 Rancière propone considerar "literatura" al modo histórico de visibilidad de unas ciertas obras del arte de escribir, un modo histórico que produce la misma separación de esas ciertas obras y, en consecuencia, los discursos que teorizan esa separación. Sostenemos, entonces, que la literatura no es ni una cosa ni una creencia infundada, sino un proceso de prácticas atravesadas por una serie particular de contradicciones que la vuelven productiva y poseedora de una historicidad constitutiva. Respecto de la "historiografía literaria", Rosa plantea que la historia de la literatura como institución está claramente ligada a la historia de las instituciones, a la historia de la cultura y a la historia a secas. Y en cuanto al carácter "nacional", el mismo crítico explicita: "La así llamada literatura argentina se opone a la literatura nacional como el Estado se opone al Pueblo" (173). 
intervenciones han denunciado los modos de selección del canon occidental y cómo esos modos -que son ideológicos y políticos- intentan pasar desapercibidos a través de la idea presuntamente inocua de "tradición"3. Lo que allí queda opacado es el proceso activo de exclusión o borramiento operado por los hacedores actuales de tradición ${ }^{4}$. En efecto, distintas investigaciones han demostrado cómo las versiones del pasado ratifican el orden presente produciendo una continuidad predispuesta del varón privilegiado de raza blanca, hecho que forma parte de un proceso complejo y de larga de data de una dominación intelectual de carácter eurocéntrico y también falocéntrico, que descansa sobre la idea de una feminidad negada para asegurar la supremacía de lo masculino en la esfera de la creatividad. A su vez, como sostiene Sylvia Molloy en "Sentido de ausencias" (1985), el canon patriarcal resulta el de más fácil acceso. Todo lo favorece: los programas universitarios, la opinión pública y los medios familiares poco dispuestos a la apertura.

A estos complejos procesos canonizadores de visibilización / invisibilización entiendo que responde el hecho de que Barrandeguy haya sido antologada en los últimos ańos de su vida en importantes volúmenes como 200 años de poesía argentina, compilado por Jorge Monteleone (2009), o, más tempranamente, en la Antología Básica Contemporánea de la Poesía Iberoamericana (1978) publicada en Colombia por Pulitzer, y post-mortem en sus Poesías Completas, que editó Ediciones del Copista en 2009. Y, sin embargo, no figura en ninguna de las colecciones de historia de la literatura argentina que se publicaron en los últimos 40 años: las colecciones dirigidas por Noé Jitrik y por David Viñas, en las cuales sí aparecen con recurrencia escritores incluso más jóvenes que Barrandeguy, como Juan José Saer (1937-2005) o Ricardo Piglia (1941-2017), como si fuera ilegible por la crítica, o por cierta crítica. $\mathrm{Y}$ a los mencionados procesos canonizadores responde también el hecho de que dentro de la crítica literaria vinculada con los estudios de género se siga recordando principalmente a la deslumbrante y censurada Monte de Venus (1976) de Reina Roffé como texto inaugural de la

3 Las discusiones en torno al canon se amplificaron notablemente en el pasaje del siglo XX al siglo XXI. En esa coyuntura salen a la luz no solo el discutido trabajo de Harold Bloom (1997) sino también otras aportaciones relevantes como las de Frank Kermode, Ítalo Calvino (Por qué leer), o Enric Sullà. Hacia el fin del milenio se sumaron a este debate otras voces, ejemplarmente, las pautas para la producción literaria formuladas por Calvino (Seis propuestas), que pueden resumirse en una serie acotada de rasgos: levedad, rapidez, exactitud, visibilidad y multiplicidad. Sin embargo, en la constitución de un canon participan otros aspectos, tales como la inclusión o no de manifestaciones de colectivos tradicionalmente excluidos del llamado "canon occidental". Allí entran en juego los postulados de ciertas áreas del conocimiento en ciencias sociales y humanas consolidadas en el siglo XX como los estudios poscoloniales, feministas, queer y neohistoricistas.

4 Más allá de la idea de catálogo que produce una ilusión de fijeza y atemporalidad, el canon no puede constituirse de una vez y para siempre. Establece respecto del pasado una tradición selectiva -"una visión intencionalmente selectiva de un pasado configurativo y de un presente preconfigurado, que resulta entonces poderosamente operativo dentro del proceso de definición e identificación cultural y social" (Williams 56) -así como una proyección hacia el futuro que es inherente a toda norma o principio. 
literatura lesbiana en la Argentina. Esa veladura o borramiento de la producción escrituraria de Barrandeguy, en algunas zonas del campo literario argentino, se saluda con entusiasmo: "Bienvenida al fuera del canon, a la línea fronteriza de la gran literatura argentina", celebraba en 2002 Diana Bellessi su "descubrimiento" de Barrandeguy.

Pero es preciso notar que, en el caso de esta autora entrerriana, el proceso de visibilización taimada de su producción tiene que ver además con una deliberada política de la escritura y con una política del cuerpo. Ambas operan y se retroalimentan mutuamente tanto en su vida como en sus ficciones. Como lesbiana que estuvo casada con un varón durante doce años, no capitalizó los posibles beneficios sociales y de pertenencia de la heterosexualidad ni de la homosexualidad. Como autora, nunca envió sus originales a medios masivos ni a editoriales de gran circulación, incluso teniendo llegada a los cenáculos intelectuales del diario Crítica y al alcance de la mano la influencia de Salvadora Medina Onrubia, su mentora. Una política y una ética que, como puntualizaré más adelante, tienen que ver con elecciones deliberadas que conectan renuncia y deseo, elecciones que aparecen ficcionalizadas con especial énfasis en su novela autobiográfica y tardíamente publicada Habitaciones.

\section{Trayectos políticos, trayectos escriturarios, trayectos de vida}

En 1937, Barrandeguy tiene 23 años y decide abandonar Gualeguay (luego de recibirse de maestra -profesión que decide no ejercer-, publicar en una edición artesanal mimeografiada un libro de poemas contestatarios, dedicado "a los amigos en la lucha”, y de militar durante cinco ańos junto a Juan L. Ortiz y Carlos Mastronardi en la agrupación afín al comunismo Claridad) y se instala en Buenos Aires. Había mantenido correspondencia durante largo tiempo con Salvadora Medina Onrubia (1894-1972), criada durante unos años en Entre Ríos, militante anarquista, feminista, dramaturga y extravagante esposa de Natalio Botana, dueño del diario Crítica.

Emma trabajó durante 22 ańos (desde 1938 hasta 1956) para los Botana, pero nunca escribió en el diario sino que se desempeńó en distintas áreas, como administrativa y como secretaria privada de Salvadora. De modo que su figura de escritora y su lugar en el campo literario no puede pensarse como equivalente, por ejemplo, al de un Roberto Arlt que por los mismos años escribía en Crítica y que construyó su ethos autoral poniendo de relieve su oficio de periodista, escenificando la cocina de su escritura en esas "redacciones estrepitosas, acosado por la obligación de la columna cotidiana" (Arlt 9).

En algunos de sus textos, Emma se narra a sí misma escribiendo poemas en la oficina, en los tiempos muertos de su trabajo como ensobradora y despachante de correspondencia. Pero si bien pueden observarse cambios notables en sus modos de escribir antes y después de Crítica, en ningún caso esa transgresión adquiere rasgos programáticos ni presupone a los actores de ese medio como 
posibles interlocutores de su obra. Su intervención es de otra índole: de baja intensidad, menor, diferida.

\section{Estrategias dislocatorias}

Como bien investigó en un trabajo reciente Evangelina Franzot, Barrandeguy emigró de su pueblo natal para no morir de frustración, rechazo y aislamiento (en la década de 1930, en la Argentina se intensificó la persecución al comunismo, en especial desde 1932 cuando se promulgó el "Proyecto de represión y calificación de comunistas" del Senador Sánchez Sorondo y con la asunción del presidente Agustín Justo, que implementó un recrudecimiento de los métodos represivos), pero en términos imaginarios nunca abandonó Gualeguay, su zona. El problema era cómo mantenerse allí sin volverse una manifestación de la literatura regional, que Barrandeguy rechazaba por burguesa y provinciana. Aquí entran en juego lo que llamo sus "estrategias dislocatorias", en referencia a un tipo de relación con el espacio público y con el campo intelectual que puede vincularse con las "tretas del débil" que Josefina Ludmer leyó a partir de la célebre Respuesta de Sor Juana Inés de la Cruz a Sor Filotea, haciendo foco en la posición de subordinación y marginalidad que ocupa una mujer en el campo del saber en una situación histórica y discursiva precisa.

En ese sentido, es productivo observar el modo en que Emma Barrandeguy ejercitó una escritura diferida en lo espacial y en lo temporal: dilató los tiempos de publicación (Poemas es de 1936 y su siguiente poemario, Las puertas, de 1964), publicó sobre Gualeguay en Buenos Aires y sobre Buenos Aires en Gualeguay. Además, escribió la biografía de Salvadora Medina Onrubia (Barrandeguy 1997) una vez que la "Venus roja", como la llamaban, había muerto.

Esta estrategia le permitió barajar un triple auto-borramiento: literario (en las entrevistas nunca habla de su producción como una obra sino como apuntes o como escritura de catarsis); político (por cuestiones de seguridad y para no disgustar a su familia -su madre era conservadora, su padre militante radical-, nunca se afilió al PC, aunque formó parte de los que Agustín Alzari llamó "La internacional entrerriana", una sociabilidad comunista que luego recuperó en Buenos Aires en otras militancias, como su trabajo en la Universidad Obrera Argentina en la década de los 50) y un auto-borramiento de su orientación sexual no heteronormativa (publicó Habitaciones, su novela autobiográfica de temática lésbica, en 2002, cuando pensaba que estaba a punto de morir, aunque falleció recién cuatro años más tarde).

Tanto en las entrevistas como en los relatos de parientes y discípulos de Gualeguay, a varios de los cuales entrevisté en el marco del proyecto de biografía y archivo de la autora que estoy llevando adelante, se conjugan dos pasiones que Emma aborrecía abiertamente: el "botanismo" y el "barrandeguismo". Sus coterráneos y familiares recalan sus relatos sobre la autora, por un lado en su importancia como testigo de la época de esplendor del diario Crítica y como 
biógrafa de Medina Onrubia, y por otro, en el orgullo de tener una escritora en el pueblo o en la familia, algo que el clan Barrandeguy (terratenientes ganaderos descendientes de inmigrantes vascos, radicados en Entre Ríos y en otras provincias argentinas) sentía finalmente que los prestigiaba, aunque hubieran leído poco o nada de su producción y se esforzaran por negar sus opciones políticas y su orientación sexual.

A pesar de esa resistencia de la autora, el efecto Botana tuvo una onda expansiva que trascendió a la parentela y al pueblo. A eso se refería la escritora cuando hablaba con ironía del "botanismo". La publicación del libro Salvadora: una mujer de Critica le dio, contra su voluntad, una notoriedad que no había conseguido con ninguna de sus publicaciones anteriores. Fue por esa biografía de su mentora, publicada en una editorial de escasa circulación, que María Moreno decidió viajar a Gualeguay en el año 2000 para entrevistarla. Fue a Moreno a quien Barrandeguy entregó el manuscrito de Habitaciones.

Esa novela, escrita a fines de la década de los 50 , expone, a partir del formato carta, las relaciones afectivas y sexuales de quien escribe, como una manera de explicarse a sí misma. Todo el libro está dedicado (y las entradas le están destinadas) a Alfredo Weiss, abogado y escritor ligado a la revista Sur, amigo cercano de la narradora (que, sin embargo, estaba casada con otro y supo tener un amante varón y dos amantes mujeres a lo largo de los ańos y casi en simultaneidad). La narradora es la propia Emma, una escritora de provincias.

Afirma Moreno en el prólogo:

Escrita mucho antes de que se teorizara sobre las minorías sexuales, Habitaciones puede leerse como algo que está por delante de ellas, en un horizonte más radical en tanto que denuncia los espejismos de toda elección, la multiplicidad de los deseos y de sus formas, "el anhelo de una puerta abierta hacia otras habitaciones, hacia nuevas experiencias". (10)

El espacio privilegiado de la novela, la habitación, no es una cifra de la reclusión doméstica sino de la transgresión. El interior burgués cambia de signo, deja de ser el recinto de lo que Erich Hobsbawn llamó "respectability", la búsqueda de respetabilidad", para ser en cambio escenario de la "incesante peregrinación tras el placer. La satisfacción física sentida como plenitud de la vida. ¡El cuerpo!" (Barrandeguy Habitaciones 39). No existe en esta novela autobiográfica la somatofobia (la falta de alusión al cuerpo característica de los textos de la cultura occidental) que José Amícola identificó en otras autobiografías de la época; por el contrario, gestos mínimos como una caricia furtiva en la pierna de una joven,

5 En palabras de Eric Hobsbawn: "No hay ningún término más difícil de analizar que el concepto de respetabilidad para la clase obrera porque expresa simultáneamente la penetración de valores y estándares de las clases medias y una actitud sin la que hubiera sido difícil alcanzar el respeto propio en la clase obrera, y sin la que un movimiento de lucha colectiva hubiera sido imposible de construir: sobriedad, sacrificio, posposición de la gratificación." (263-364) 
por debajo de una manta, en el asiento trasero de un auto, son narrados con meticulosidad.

\section{Ser diferente, estar en contra, suscitar}

La voz narrativa que construye la trama, estructurada en cincuenta capítulos breves, todos en segunda persona, dirigidos a Alfredo, es la voz de un yo que se auto-examina. Poner al escritor en el banquillo, para esta autora, al igual que para muchos de los escritores argentinos afines al existencialismo por esos años -como aquellos nucleados alrededor de la revista Contorno (Avaro y Capdevila)-, será condición sine qua non de la escritura, pero Barrandeguy no se detuvo solo en el juicio sobre otros/as escritores/as sino que llevó al extremo su propio enjuiciamiento. En el Capítulo 7, por ejemplo, la narradora afirma: "Sin este examen conjunto de autor y lector buscando esclarecer (no describir ni fotografiar la rosa solamente) no hay nada valedero en lo que el artista hace. Proponerse la sola belleza parece absurdo y tonto" (Barrandeguy Habitaciones 47). Conforme avanza el auto-examen, se consolida una reflexión sobre los modos de vivir y de escribir, una ética que se asienta en tres máximas: ser diferente, estar en contra y suscitar.

Ser diferente en la vida y en la escritura, ser diferente por la escritura, son motivos que resuenan en todos los capítulos de la novela: "Por qué despierta uno un día cualquiera para saberse distinto? [...] A veces siento que sólo están de mi lado [...] todos los resentidos, los hambrientos, los que carecieron de algo, de dientes, de afecto, los que en cualquier momento se han sentido parias sin saberlo." (40). Pero este ser diferente en y por la escritura no constituye un regodeo en la idea de elitismo intelectual ni de gueto contracultural, sino que se asume en la marginalidad más absoluta que lidia con el desdén, tanto de los integrados al sistema como de sus camaradas militantes de izquierda. Más adelante la narradora afirma: “...el que centra su vida en la acción social mira a la gente como yo, con sonrisa desdeñosa [...] De los que aceptan la realidad social tal cual es sólo merecemos desprecio. De los de abajo porque sólo somos palabras. De los de arriba, porque sólo somos palabras. Los marginales traemos embrollos al derecho de propiedad" (41). La diferenciación, entonces, no anhela una distinción sino que se enlaza con otra máxima, la de estar en contra, emulando explícitamente aquel extenso y controvertido poema de Raúl González Tunón titulado "Las brigadas

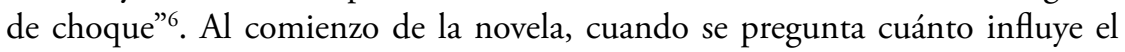
ambiente en la construcción de una persona, la narradora asegura:

6 El fragmento final del poema de Tunón espeta: "Le falta a Buenos Aires la Tercera Fundación / La que vendrá con la Revolución / ¡Preparémonos para tirar! / Contra los museos, / las universidades, / la prensa / paquidermo, / la radiotelefonía, la academia, / el teatro y el deporte burgueses. / Preparémonos para tirar / y acertar esta vez. / Contra en la casa / contra en el mar / contra en la calle / contra en el bar / contra en la montaña. / Para abatir al imperialismo. / Por una conciencia revolucionaria. / Y aquí nosotros contra la histeria fascista, / contra el socialismo tibio,/ contra la confusión Radical, / contra / contra / estar contra / sistemáticamente contra / contra / contra./ 
Existe la reacción en contra, antes que la imitación. Las lecciones no tienen la validez que puede tener una conducta. De eso no se daban cuenta los ancestros. Tal vez no tenían tiempo de darse cuenta. Pero creo que era debido a la cáscara. Donde la cáscara se agujereaba, donde se producía el resquicio que daba lugar a la crítica, empezaba la reacción en contra, que es la que permite crecer." (24, énfasis mío).

Ser diferente -en la vida y en las ficciones de Barrandeguy- también significa admitir que se enamoró de un hombre (un acróbata norteamericano) y estuvo casada con él durante doce años, pero también mantuvo relaciones paralelas con otros hombres y con mujeres, desafiando los preceptos tanto de la heteronormatividad como los de la homonormatividad ${ }^{7}$.

En relación con este último punto, es preciso señalar que la trama de $\mathrm{Ha}$ bitaciones también configura masculinidades alternativas, que se apartan de las llamadas "masculinidades hegemónicas" (Connell). Alfredo, el destinatario de todo lo que la protagonista va contando como en una conversación, no solo es su confidente sino también un compañero de lecturas y un interlocutor que discute a la par en torno a las preocupaciones intelectuales y políticas de la narradora. Neil Mac Donald, el marido, compone a su vez una figura no tradicional para la década de 1950 -en la cual se sitúa el presente de la enunciación- ya que es artista, comparte ciertos espacios públicos, como bares y cafés, con la narradora, y le da la suficiente libertad para que pueda continuar con su trabajo en el diario, su militancia política y sus aventuras amorosas.

Por último, es recurrente en las ficciones de Barrandeguy la acción de suscitar, verbo que abre la puerta a todas las escenas eróticas de Habitaciones y a las reflexiones sobre esos acercamientos:

...lo que pago es no haberme resignado a no suscitar amor, el poseer aún esta necesidad de amor, el no haber aceptado cómo las cosas son, ni el sosiego de los años. Mis ojos y mi cuerpo creyeron aun en su derecho a la dicha física, no a la plenitud del 'ser interior'. Porque entiendo que este 'ser' debe o puede surgir cuando ya nada nos envenena dentro, ningún deseo. (49, énfasis mío)

O más adelante: "Reconozco haber originado las vinculaciones que creaban alrededor mío una red sentimental. Pero el defecto no está en crear o suscitar

¡Yo arrojo este poema violento y quebrado / contra el rostro de la burguesía!” (escrito en 1935, publicado en La rosa blindada, $\mathrm{N}^{\mathrm{o}}$ 4, marzo de 1965).

7 El concepto de "heteronormatividad" fue acuñado por Michael Warner, quien postula que la heterosexualidad no solo se convierte en la norma sexual por excelencia, sino en la única opción posible, concepción que tiene claras influencias de teóricas como Monique Wittig -que piensa esa norma en términos de contrato social-y Adrienne Rich, quien destaca su carácter de obligatoriedad. Cuando estas ideas se repiten en la homosexualidad puede hablarse de "homonormatividad". De acuerdo con Lisa Duggan, la homonormatividad implica mantener parámetros heteronormativos en las vidas homosexuales, cuando dichas orientaciones sexuales podrían ser la base de construcción de nuevos modos de vida. 
vinculaciones -es imposible no hacerlo- sino en la medida en que la ligazón se haga obsesiva" (50). Se refiere a lo tormentoso de la relación con su segunda amante, la más joven, Florencia, que enferma de celos y, como consecuencia, la novela termina con una muerte.

Me interesa la recurrencia del verbo suscitar porque remite a una provocación decidida pero discreta y paciente - "Siempre éramos discretos en lo que se refería a nuestras intimidades. Vos en tus cosas, yo en las mías" (56), le dice a Alfredo- que reaparecerá medio siglo más tarde en los modos de ficcionalizar el homoerotismo en sus poemas, publicados póstumamente. En 2003, por ejemplo, escribe el poema "Carolina", que envía a su última amante -cincuenta años menor y con la que además comparte lazos de sangre-, del cual vale la pena citar los primeros versos para notar el modo discreto en que poetiza el incesto: "Besarás en el cuerpo / de esta anciana que camina / hacia su muerte / a tu padre / o al mío / en nuestra enmarañada / sangre / y yo besaré tu hombro desnudo / con delicia / como si mis manos tocaran / flores delicadas / Te aguardo sin decirte todo esto que ansío de vos" (Barrandeguy Poesías 95). De 2006 data otro breve poema sin título: "Gocemos escondidos. / Enmudezcamos./ ¿Fue siempre así mi goce? / ¿Fue necesario hacerlo? / O el goce es simple / como comer arroz / como ver la rosa / o el brote, / como acariciar el gato? / La que dice desearme / ¿dice verdad? / Qué puedo ofrecer a sus ojos: / Dímelo vieja Safo / y estaré y estaremos contigo" (380).

Está en lo cierto parcialmente entonces Diana Bellessi cuando caracteriza a Emma Barrandeguy como una "fuera de lugar" y da la bienvenida a Habitaciones "al fuera del canon". Bien mirada, Barrandeguy estuvo más bien fuera del tiempo: se adelantó como a los imperativos de su época y escribió para la nuestra. Por eso, la edición tardía de Habitaciones reorganiza el canon y la tradición. Hacia el final de la novela, la narradora cuenta que entre los trabajos que le tocaban como secretaria personal de Salvadora estaba: "aguantar sus caprichos, beber whisky, ayudar a que el nieto coma" (145). Fue ella quien le dio de comer al nieto de los Botana, ese niño que después se transformaría en Copi (1939-1987). Reconstruir una tradición, como propuso Daniel Link, es explicar quién se alimenta de quién (y de quiénes nos alimentamos nosotros).

En este punto se abre un interrogante: ¿qué sentido tiene para nosotros/as leer Habitaciones, ese manuscrito de cien páginas escritas en la década de 1950 y escondidas durante medio siglo, además de sumar una pieza pionera en el rompecabezas de las escrituras queer en la argentina? ${ }^{8} \mathrm{O}$, en otros términos: ¿qué sentido

8 A partir de finales de la década de 1980, la palabra queer -que en inglés funcionaba insulto e injuria contra homosexuales y todos/as aquellos/as cuya conducta, apariencia o "estilo de vida" no se ajustara a las normas imperantes- comenzó a ser reclamada de su uso peyorativo como un autoidentificador neutral o positivo por sujetos y colectivos activistas que cuestionaban las categorías identitarias, incluyendo las gais y lesbianas. De ese modo, la injuria se resignificó con fuerza contestataria. Teniendo en cuenta esta periodización, puede pensarse que la producción de Emma Barrandeguy integraría el archivo de la literatura queer en tanto precursora o avant la lettre. Laura Arnés ha leído Habitaciones como parte de las ficciones lesbianas de la literatura 
tiene leer a Emma Barrandeguy en y desde el presente? En relación con esto, quisiera recuperar brevemente dos aportaciones críticas de los últimos años que se presentan como iluminadoras respecto de, por un lado, la relevancia de revisitar el archivo de la literatura queer de la primera mitad del siglo XX, y por otro, con la necesidad de pensar nuevas éticas y políticas identitarias que sostengan modos de vida diversos no exclusivamente basados en la búsqueda de visibilización.

La primera de esas propuestas es la que realiza Heather Love en Feeling Backward. Allí la autora argumenta que, en la cultura contemporánea, si bien la tolerancia cada vez mayor para el matrimonio entre personas del mismo sexo y los medios homosexuales traen beneficios, la asimilación gay implica también ciertas pérdidas que han sido difíciles de identificar o lamentar, ya que muchos aspectos de la cultura gay histórica están estrechamente asociados al dolor y la vergüenza del armario. A lo largo del libro, Love hace un esfuerzo por valorar aspectos de la experiencia gay que ahora parecen en vías de desaparecer, experimentados como restos vergonzosos de los malos viejos tiempos anteriores a Stonewall. Por una parte, examina una serie de novelas gais de principios del siglo XX, muchas veces desatendidas por ser poco orgullosas o "demasiado deprimentes". Por otra parte, se pregunta cómo podemos recuperar y poner en valor los oscuros sentimientos que representan, enfatizando que, en lugar de seguir adelante, tenemos que mirar hacia atrás y considerar cómo esta historia continúa afectándonos en el presente. Es este uno de los sentidos de revisitar una producción literaria como la de Emma Barrandeguy: conectar con una escritura pretérita sustentada en una experiencia de exclusión social por diferencia sexual que a su vez es solidaria con otros modos de opresión, en un momento en el que, en cambio, lo que abunda son los relatos autocelebratorios.

La segunda contribución crítica que me parece relevante mencionar es la de Denilson Lopes en el capítulo "Por una nueva invisibilidad" del volumen Fragmentos de lo queer, compilado por Lucas Martinelli. Allí Lopes lee un conjunto de ficciones de Silviano Santiago y Caio Fernando Abreu que considera una alternativa a los discursos sobre la visibilidad (hegemónicos entre los grupos militantes en las ciencias sociales) y en las que reconoce estrategias identitarias atendibles, más sutiles y menos confrontacionistas, dentro de un contexto posidentitario y transcultural. En ese marco, aboga por una "nueva invisibilidad":

Si la invisibilidad comúnmente tiene un sentido negativo en un primer momento de una política de las identidades, tal vez ahora ella pueda significar algo diferente. Ser invisible en una sociedad consumista puede ser una manera de hacer una diferencia por la pausa y sutileza. En una sociedad donde todo, todos deben ser visibles a cualquier costo, incluyendo más y más diversos grupos minoritarios, incluso la transgresión y la diferencia son apenas es-

argentina, más específicamente, dentro de la tradición del género de la ficción autobiográfica, junto con textos de Sylvia Molloy y Gabriela Massuh. 
trategias de marketing. Por cierto, invisibilidad no significa esconderse, huir de la realidad, sino simplemente una forma de enfrentar el poder corrosivo del simulacro, el exceso de imágenes y signos, cada vez más desprovistos de sentido. (56)

Más adelante, en diálogo con Paul Virilio y su Estética de la desaparición, se pregunta: "¿Cómo sería posible, hoy entonces, no sólo una estética sino una ética encarnada en la desaparición, en tiempos de máxima exposición cuando el marginal, el revolucionario, el alternativo, el independiente, el minoritario son glamourizados, vendidos, empaquetados?” (61). Políticas de la escritura y políticas del cuerpo como las de Emma Barrandeguy caen en nuestras manos en diferido justamente para interrumpir la ilusión teleológica de progreso indefinido de las condiciones de vida e iluminar discretamente algunas de estas preguntas.

\section{Referencias bibliográficas}

Amícola, José. Autobiografía como autofiguración. Estrategias discursivas del Yo y cuestiones de género. Beatriz Viterbo - CINIG, 2007.

Arlt, Roberto. Los lanzallamas. 1931. Compañía General Fabril Editora S.A, 2004.

Arnés, Laura. Ficciones lesbianas. Literatura y afectos en la cultura argentina. Madreselva, 2016.

Avaro, Nora y Analía Capdevila. Denuncialistas. Literatura y polémica en los '50. Santiago Arcos, 2004.

Barrandeguy, Emma. Poesías completas. Ediciones del Copista, 2009. . Habitaciones. Catálogos, 2002.

Bloom, Harold. El canon occidental: la escuela y los libros de todas las épocas. Traductor Damián Alou. 1993. Anagrama, 1997.

Calvino, Ítalo. Por qué leer a los clásicos. Traductora Aurora Bernárdez. 1991. Tusquets, 1993.

- Seis propuestas para el próximo milenio. Traductores Aurora Bernárdez y César Palma. 1988. Siruela, 2014.

Connell, Raewyn. Masculinities. University of California, 2005.

Duggan, Lisa. The Twilight of Equality? Neoliberalism, Cultural Politics, and the Attack on Democracy. Beacon Press, 2004.

Franzot, Evangelina. Cronosintesis. EDUNER, 2016.

Kermode, Frank. Forms of Attention. University of Chicago, 1985. 
Link, Daniel. Clases: literatura y disidencia. Norma, 2005.

Lopes, Denilson. "Por una nueva invisibilidad". Fragmentos de lo queer. Arte en América Latina e Iberoamérica. Compilador Lucas Martinelli. Secretaría de Publicaciones de la Facultad de Filosofía y Letras de la Universidad de Buenos Aires, 2016, pp. 23-39.

Love, Heather. Feeling Backward. Loss and the Politics of Queer History. Harvard University, 2009.

Ludmer, Josefina. "Las tretas del débil". La sartén por el mango. Ediciones El Huracán, 1985, pp. 20-27.

Molloy, Sylvia. "Sentido de ausencias". Revista Iberoamericana, vol. LI, no 132133, 1985, pp. 433-438. https://doi.org/10.5195/reviberoamer.1985.4061

Moreno, María, "Emma, la del gremio". Página/12. 9 de marzo de 2012. https:// bit.ly/2LLry8z, consultado 12/06/18.

Pollock, Griselda. "Disparar contra el canon. Acerca de cánones y guerras culturales". Mora, no 8, 2002, pp. 55-67.

Nun, José. "La rebelión del coro". Nexos, no 46, 1981, pp. 19-16

Rancière, Jacques. La palabra muda. Ensayo sobre las contradicciones de la literatura. Traductora Cecilia González. Eterna Cadencia, 2009.

Rosa, Nicolás, editor. Politicas de la crítica. Historia de la crítica literaria en la Argentina. Biblos, 1999.

Sullà, Enric, editor. El canon literario. Arco Libros, 1998.

Warner, Michael. "Introduction: Fear of a Queer Planet", Social Text, no 29. 1991, pp. 3-17.

Williams, Raymond. Palabras clave. Un vocabulario de la cultura y la Sociedad. Traductor Horacio Pons. 1976. Nueva Visión, 2003.

Fecha de recepción: 14/03/2018 | Fecha de aceptación: 08/06/2018 